\title{
Changes in the expression and cytological localization of betacellulin and its receptors (ErbB-1 and ErbB-4) in the trophoblasts in human placenta over the course of pregnancy
}

Kenji Tanimura, Satoshi Nakago, Homare Murakoshi, Shigeki Takekida, Toshitake Moriyama, Hiroya Matsuo, Kimio Hashimoto ${ }^{1}$ and Takeshi Maruo

Department of Obstetrics and Gynecology, Kobe University Graduate School of Medicine, Kobe 650-0017, Japan and ${ }^{1}$ Pathology Division,

Nishi-Kobe Medical Center, Kobe, Japan

(Correspondence should be addressed to T Maruo; Email: maruo@kobe-u.ac.jp)

\begin{abstract}
Objective: Betacellulin (BTC), purified and cloned from mouse beta cell tumor (BTC-JC10), is regarded as a new member of the epidermal growth factor family. The present study was conducted to clarify the expression of BTC and its receptors, ErbB-1 and ErbB-4, in the trophoblasts in the human placenta over the course of pregnancy.

Design and Methods: Human placental tissues were obtained from 4 pregnant women at the 4th to 5th week of pregnancy (very early placentas), 10 women at the 6th to 12th week (early placentas), 5 women at the 18th to 21 st week (mid placentas) and 8 women at the 38 th and 40 th week (term placentas). The mRNA expressions of BTC, erbB-1 and erbB-4 were evaluated by quantitative RTPCR with Southern blotting and the expression of the soluble form of BTC was determined by western immunoblot with a specific antibody to BTC protein. Immunohistochemical staining of BTC, ErbB-1 and ErbB-4 was also performed.

Results: The levels of BTC mRNA expression in early and mid placentas were significantly higher than those in term placentas. The soluble form of BTC protein with an estimated molecular mass of $9.5 \mathrm{kDa}$ was expressed in early and mid placentas, whereas the soluble form was not detected in term placentas. BTC from very early placentas until mid placentas was immunolocalized in syncytiotrophoblasts (S-cells), and was most abundant in early placentas. In contrast, BTC was immunolocalized in extravillous trophoblasts (EVTs), but not in villous trophoblasts in term placentas. The levels of erbB-1 mRNA in the early and mid placentas were significantly higher than those in term placentas, whereas the levels of erbB-4 mRNA in early placentas were significantly lower than those in mid and term placentas. ErbB-1 was immunolocalized in cytotrophoblasts in very early placentas, whereas it was immunolocalized in S-cells from early until term placentas. ErbB-4 from very early placentas until mid placentas was immunolocalized in S-cells, whereas ErbB-4 in the term placentas was detected in EVTs, but not in villous trophoblasts.

Conclusions: These findings provide evidence for changes in expression and cytological localization of BTC and its receptors in the trophoblasts in human placenta over the course of pregnancy. BTC may play a pivotal role as a local growth factor in promoting the differentiated villous trophoblastic function via ErbB-1 in early placentas and in contributing to placental growth through the maintenance of EVT cell function via ErbB-4 in term placentas.
\end{abstract}

European Journal of Endocrinology 150 93-101

\section{Introduction}

The trophoblasts include the villous trophoblasts consisting of cytotrophoblasts (C-cells) and syncytiotrophoblasts (S-cells), and extravillous trophoblasts (EVTs). In our previous reports, we have shown that placental growth is characterized by the proliferative activity of C-cells and the expression of Bcl-2 protein, an apoptosis-inhibiting gene product, in S-cells $(1,2)$, which decreases in the placenta complicated with severe pre-eclampsia or intrauterine growth restriction (3). The placental growth is regulated by endocrine factors and/or local growth factors $(4,5)$. The dynamic change in cytological localization of epidermal growth factor (EGF) and EGF receptor is observed in human villous trophoblasts $(6,7)$. We demonstrated that EGF exerts a gestational age-dependent dual action as an autocrine local factor on the first trimester placenta: one is to stimulate trophoblast proliferation in 4-5 week placentas and the other is to 
stimulate differentiated trophoblast function in 6-12 week placentas $(8,9)$. Moreover, EGF prevents tumor necrosis factor- $\alpha$-induced apoptosis in cultured term trophoblasts (10) due to the stimulation of fibronectin production by trophoblasts (11). These findings indicate that EGF plays a vital role in human placental growth.

The EGF family, consisting of at least 15 members (12), is characterized by a six-cysteine consensus motif and forms three intramolecular disulfide bonds (13). These proteins are initially synthesized as transmembrane precursor peptides that are secreted by proteolytic cleavage of the extracellular domain and bind to erbB tyrosine kinase receptors (ErbB-1, ErbB2, ErbB-3 and ErbB-4) as either membrane-anchored precursor peptides or soluble mature hormones. Betacellulin (BTC), which belongs to the EGF family, is a polypeptide growth factor that was initially described, purified and cloned from a mouse insulinoma cell line, BTC-JC10 $(14,15)$. BTC is known to bind ErbB-1 (classical EGF receptor) and ErbB-4. BTC is a potent mitogen for a wide variety of cell types, including vascular smooth muscle cells and pigment epithelial cells, with a potency nearly identical to that of EGF $(14,16)$. BTC also acts as a differentiation factor of the pancreatic tumor cell line AR42J (17) and in glucagonoma cells (18). Several peptides of the EGF family members, transforming growth factor- $\alpha$, amphiregulin and heparin-binding EGF-like growth factor (HB-EGF), have been identified in human placenta (19-21). Little information is, however, available regarding the evidence for the expression of BTC in the trophoblasts in human placenta. The present study was conducted to clarify the expression of BTC and its receptors, ErbB-1 and ErbB-4, in the human placenta over the course of pregnancy. The mRNA expression of BTC, erbB- 1 and erbB-4 was evaluated by quantitative RT-PCR with Southern blotting and the expression of BTC protein was determined by western immunoblot. Immunohistochemical analysis of BTC, ErbB-1 and ErbB-4 was also performed

\section{Materials and methods}

\section{Placental materials}

First trimester placentas were obtained from 14 patients who underwent elective abortion at the 4th to 5 th week (very early placentas; 4 cases) and the 6th to 12 th week (early placentas; 10 cases) of pregnancy. Second trimester placentas were obtained from 5 patients who had therapeutic abortion between the 18th and 21st week (mid placentas) of pregnancy. Third trimester placentas were obtained from 8 patients who had elective cesarean section between the 38th and 40th week of pregnancy with varied identifications such as repeated cesarean section and breech presentation (term placentas). The gestational age of the placenta was determined by estimation of the duration of pregnancy from the date of the patient's last menstrual period. In all cases, gestational age was further evaluated by ultrasonographic examination. None of the women was on any kind of medication, all denied smoking, and none had any concurrent medical illness. The collection of placental tissues has been approved by the Medical Ethics Review Committee of the Kobe University Graduate School of Medicine. Informed consent for the use of placental tissues for the present study was obtained from each patient before the operative intervention. Villous tissues free of visible infarct, calcification or hematoma were sampled.

The placental tissues obtained were immediately frozen at $-80{ }^{\circ} \mathrm{C}$ or fixed in $4 \%$ buffered neutral formaldehyde solution, dehydrated and embedded in paraffin. Sections of $4 \mu \mathrm{m}$ were deparaffinized following standard histological techniques.

\section{Quantitative RT-PCR analysis with Southern blotting}

Quantitative RT-PCR analysis with Southern blotting was performed as previously described (22). Total RNA was isolated from frozen placental tissues using an RNeasy Mini Kit (QIAGEN, GmbH, Hilden, Germany) according to the manufacturer's protocol. First strand complementary DNA (cDNA) was synthesized from $4 \mu \mathrm{g}$ total RNA using a cDNA synthesis kit (QIAGEN) according to the manufacturer's protocol. PCR was performed using $0.1 \mu \mathrm{g}$ cDNA as template in a $25 \mu \mathrm{l}$ reaction buffer $(10 \mathrm{mmol} / \mathrm{l}$ Tris-HCl, pH 8.3, $50 \mathrm{mmol} / \mathrm{l}$ $\mathrm{KCl}, 1.5 \mathrm{mmol} / \mathrm{l} \mathrm{MgCl}_{2}$ and $0.01 \%$ gelatin) containing $6.25 \mathrm{pmol} / \mathrm{l}$ of each primer, $2.5 \mathrm{mmol} / \mathrm{l} \mathrm{dNTPs}, 0.125$ $\mathrm{U}$ taq DNA polymerase (all from QIAGEN). Reactions were amplified by a Gene Amp PCR System 9600-R (Perkin Elmer Corp., Norwalk, CT, USA), using the following thermal profile: initial denaturation step at $95^{\circ} \mathrm{C}$ for $5 \mathrm{~min}$, followed by 20 or 21 cycles of denaturation at $94{ }^{\circ} \mathrm{C}$ for $1 \mathrm{~min}$, annealing at $55^{\circ} \mathrm{C}$ for $1 \mathrm{~min}$, extension at $72^{\circ} \mathrm{C}$ for $1 \mathrm{~min}$ and a final elongation of $72^{\circ} \mathrm{C}$ for $5 \mathrm{~min}$. Primers for BTC (sense primer: $5^{\prime}$-TTCACTGTGTGGTGGCAGATGG- $3^{\prime}$ and antisense primer: 5'-ACAGCATGTGCAGACACCGATG-3') and erbB-1 (sense primer: 5'-CAGCGCTACCTTGTCATTCAG- $3^{\prime}$ and antisense primer: 5'-TCATACTATCCTCCGGGTCA-3') were synthesized according to the report by Adam et al. (23). Primers for erbB-4 (sense primer: 5'-TCCAGCCCAGCGATTCTCAG-3' and antisense primer: 5'-GGCCAGTACAGGACTTATGG-3') were synthesized according to the report by Patel et al. (24). Separate reactions were performed using primers specific for $\beta$-actin (sense primer: 5'-CTTCTACAATGAGCTGCGTG-3' and antisense primer: 5'-TCATGAGGTAGTCAGTCAGG-3'). The PCR product specific for $\beta$-actin was visualized under ultraviolet light following gel electrophoresis on a $1.5 \%$ agarose gel stained with ethidium bromide. 
The PCR products specific for BTC, erbB- 1 and erbB-4 were electrophoresed on 3\% agarose gel and transferred to a nylon membrane filter for Southern blotting after denaturation with alkaline solution. The DNA on the membrane was fixed by UV irradiation. Subsequently, $5^{\prime}{ }^{32} \mathrm{P}$ end-labeled oligonucleotide probes specific for BTC (5'-ACTGCATCAAAGGGAGATGCCGCTT- $\left.3^{\prime}\right)$, erbB-1 (5'-ATAGACGACACCTTCCTCCCAGTGCCTG-3') or erbB-4 (5'-GAACTTGACAGAAATCCTAAATGGT GGAG-3') were allowed to hybridize to membranes at $65^{\circ} \mathrm{C}$ for $18 \mathrm{~h}$ after prehybridization at $65^{\circ} \mathrm{C}$ for $2 \mathrm{~h}$. The probe specific for $\beta$-actin was the full-length cDNA of $\beta$-actin labeled with ${ }^{32} \mathrm{P}$. All primers and cDNA probes in the present study were synthesized by Gibco Life Technologies (Paisley, Strathclyde, UK). Membrane washing was allowed to proceed twice by washing buffer $(300 \mathrm{mmol} / \mathrm{l} \mathrm{NaCl}$ and $30 \mathrm{mmol} / \mathrm{l}$ trisodium citrate, $\mathrm{pH} 7.0$ ) with $0.1 \%$ sodium dodecyl sulfate (SDS) at room temperature for $20 \mathrm{~min}$, followed by incubation in a buffer $(30 \mathrm{mmol} / \mathrm{l} \mathrm{NaCl}$ and $3 \mathrm{mmol} / \mathrm{l}$ trisodium citrate, $\mathrm{pH} 7.0$ ) with $0.1 \%$ SDS at $60^{\circ} \mathrm{C}$ for $5 \mathrm{~min}$. Membranes were visualized by exposure to X-Omat film (Eastman Kodak Co., Rochester, NY, USA). The radioautograms were then scanned with Scanjet 3 C/ADF (Hewlett Packard, Miami, FL, USA) and quantified with NIH Image ver 1.58 (NIH, Bethesda, MD, USA). The amount of mRNA was expressed relative to the abundance of $\beta$-actin mRNA. Data were presented as fold increases over the control value and the mean \pm standard deviation (S.D.). The PCR products were cloned and sequence analysis revealed their specificity.

\section{Protein extraction and western immunoblotting for BTC}

Proteins were extracted from frozen placental tissues as described previously (25). Frozen placental tissues were lysed at $4^{\circ} \mathrm{C}$ for $30 \mathrm{~min}$ in the presence of a lysis buffer $(150 \mathrm{mmol} / \mathrm{l} \mathrm{NaCl}, 1 \mathrm{mmol} / \mathrm{l}$ phenylmethylsulfonylfluoride, $1 \mathrm{mmol} / \mathrm{l}$ EDTA, $20 \mathrm{mmol} / \mathrm{l}$ HEPES, $12 \mathrm{mmol} / \mathrm{l}$ deoxyholic acid, $35 \mathrm{mmol} / \mathrm{l} \mathrm{SdS}, 10 \mathrm{mmol} / \mathrm{l}$ D-L-dithiothreitol, 1\% Triton X). The lysates were subsequently centrifuged at $13000 \times \boldsymbol{g}$ for $30 \mathrm{~min}$ at $4{ }^{\circ} \mathrm{C}$ and supernatants were collected. The protein content in the supernatants was determined by the Bradford assay (26), with BSA as a standard.

Each of the $200 \mu \mathrm{g}$ aliquots of proteins extracted from tissues was separated by $14 \%$ SDS-polyacrylamide gel electrophoresis (PAGE) under reducing conditions using $100 \mathrm{~V}$ for $2-3 \mathrm{~h}$. The proteins were then electrophoretically transferred from gels to nitrocellulose membranes (Bio Rad Laboratories, Inc., Hercules, CA, USA). Blots were exposed overnight with a goat polyclonal antibody against human recombinant BTC (R\&D Systems Inc., Minneapolis, MN, USA), which recognized the soluble form of BTC protein, at a dilution of 1:100 in blocking buffer. The membranes were incubated for $1 \mathrm{~h}$ with horseradish peroxidase conjugated donkey anti-goat secondary antibody (Santa Cruz Biotech, Santa Cruz, CA, USA) that was diluted 1:2000 with blocking buffer. The antigen-antibody complexes were detected with an ECL chemiluminescence detection kit (Amersham Pharmacia Biotech). Membranes were visualized by exposure to X-Omat film (Eastman Kodak Co.). The radioautograms were then scanned and quantified with ChemiImager 4400 (Astec Co. Ltd, Osaka, Japan).

\section{Immunohistochemical staining}

Immunohistochemical staining was performed utilizing the avidin/biotin immunoperoxidase method with the use of a polyvalent immunoperoxidase kit (Omnitags, Lipshaw, MI, USA) as previously described (27). After washing with phosphate-buffered saline, the sections were immersed in $3 \% \mathrm{H}_{2} \mathrm{O}_{2}$ to inhibit endogenous peroxidase activity. A goat polyclonal antibody against human BTC (R\&D System Inc.) and mouse monoclonal antibodies against ErbB-1 (Neo Markers Inc., Fremont, CA, USA) and ErbB-4 (Neo Markers Inc.) were used as primary antibodies. EVTs in term placentas were identified by immunostaining with monoclonal antibodies against ErbB-2 (Neo Markers Inc.) and cytokeratin 7 (Novocastra Laboratories Ltd, Newcastle upon Tyne, UK), which are reliable markers for the identification of EVTs $(28,29)$. To improve the staining efficacy of ErBb-2 and cytokeratin 7, we used the antigen retrieval method (30). The specimens for immunostaining of ErbB-2 and cytokeratin 7 were heated to $120^{\circ} \mathrm{C}$ in $10 \mathrm{mmol} / \mathrm{l}$ citrate buffer, $\mathrm{pH}$ 6.0. The antibodies against BTC and ErbB-1 proteins as well as those against ErbB2 and cytokeratin 7 proteins were diluted 1:100 before use. The antibody against ErbB-4 was diluted 1:40 before use. The first incubation was performed with the primary antibody followed by the second incubation with biotinylated polyvalent antibody. The third incubation was carried out with avidin-horseradish peroxidase. Thereafter, the chromogenic reaction was developed by incubation with a freshly prepared solution of 3-amino-9-ethyl-carbazole with $3 \% \mathrm{H}_{2} \mathrm{O}_{2}$. The sections were counter-stained with Harris hematoxylin, mounted in glycerin phosphate buffer solution and examined microscopically.

The following control procedures were undertaken to assure the specificity of immunological reactions: adjacent control sections were subjected to the same immunoperoxidase method, except that the primary antibodies to BTC, ErbB- 1 and ErbB- 4 proteins were replaced by non-immune goat or murine IgG (Miles, Elkhart, IN, USA) at the same dilution as the specific primary antibody. The replacement of the specific primary antibody with non-immune goat or murine $\operatorname{IgG}$ resulted in a lack of positive immunostaining. The intensity of immunostaining was evaluated by repeated staining of the same specimens and by comparing the results of more than two observers. 


\section{Statistical analysis}

Statistical analysis was performed using one-way ANOVA with StatView 5.0 software (SAS Institute, Inc., Cary, NC, USA) for Macintosh, followed by post hoc testing using Fisher's protected least-significantdifference test. Differences with a $P<0.05$ were considered statistically significant.

\section{Results}

\section{BTC expression in human placenta}

BTC mRNA expression in placental tissues was identified by RT-PCR analysis throughout pregnancy. Quantitative RT-PCR with Southern blot analysis revealed that the levels of BTC mRNA in the early placentas were comparable to those in mid placentas and that
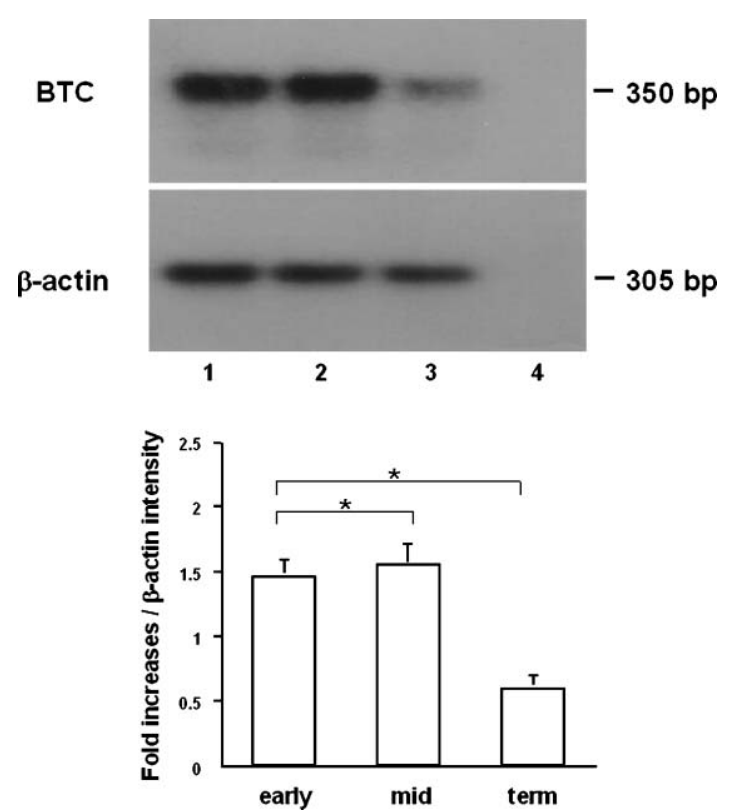

Figure 1 (Upper panel) BTC mRNA expression in human placentas, as assessed by quantitative RT-PCR analysis with Southern blotting. First strand cDNA was synthesized from total RNA extracted from early, mid and term placental tissues. Each $0.1 \mu \mathrm{g}$ cDNA was subjected to RT-PCR with Southern blotting as described in Materials and methods. The $350 \mathrm{bp}$ PCR product specific for BTC and the $305 \mathrm{bp}$ PCR product specific for $\beta$-actin were detected on the nylon membrane by the radioautograms. Experiments were repeated four times with similar results for each. Lane 1, early placenta; lane 2 , mid placenta; lane 3 , term placenta; lane 4, negative control. (Lower panel) Densitometric analysis of BTC mRNA levels in human placenta was performed as described in Materials and methods. The amount of BTC mRNA was expressed relative to the abundance of $\beta$-actin mRNA. Data are presented as the fold increases over the average intensity of $\beta$-actin mRNA expressed from early until term placentas. Each value is expressed as the mean \pm S.D.; ${ }^{\star} P<0.01$. The levels of BTC mRNA in the early placentas were comparable to those in mid placentas, whereas they were significantly higher than those in term placentas. they were significantly higher than those in term placentas (Fig. 1). Western immunoblot analysis with a specific antibody to recombinant BTC protein indicated that the soluble form of BTC protein with an estimated molecular mass of $9.5 \mathrm{kDa}$ was expressed in early and mid placentas. In contrast, the band was not detected in term placentas. Densitometric analysis showed that there was no significant difference in the levels of the soluble form of BTC protein between early placentas and mid placentas (Fig. 2). BTC in villous trophoblasts was immunolocalized in S-cells, but not in C-cells from very early until mid placentas, and was less abundant in very early and mid placentas and more abundant in early placentas (Fig. 3A-C). No immunostaining of BTC was detected in EVTs in early and mid placentas (data not shown). Also, no immunostaining of BTC was noted in villous trophoblasts in term placentas (Fig. 3D), whereas BTC was immunolocalized in EVTs in term placentas (Fig. 3E, G). EVTs in term placentas were identified with ErbB-2 immunostaining (Fig. 3F) as well as with cytokeratin 7 immunostaining (data not shown). Replacement of the primary antibody with non-immune goat IgG resulted in a lack of positive immunostaining in the cytoplasm of S-cells of early term placentas (Fig. 3H).

BTC
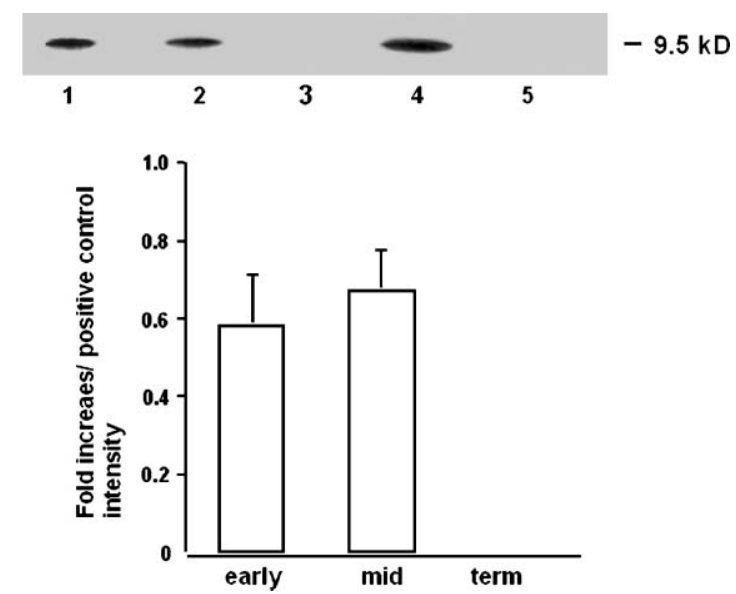

Figure 2 (Upper panel) BTC protein expression in human placentas, assessed by western immunoblot analysis. Each $200 \mu \mathrm{g}$ aliquot of proteins extracted from human placental tissue was subjected to western immunoblotting with a polyclonal antibody to recombinant BTC protein as described in Materials and methods. Experiments were repeated four times with similar results for each. Lane 1, early placenta; lane 2, mid placenta; lane 3, term placenta; lane 4, positive control (recombinant human BTC $50 \mathrm{ng}$ ); lane 5, negative control. (Lower panel) Densitometric analysis of BTC protein levels in human placenta was performed as described in Materials and methods. Data are presented as the fold increases over the intensity of positive control. Each value is expressed as the mean \pm S.D. The soluble form of BTC protein with an estimated molecular mass of $9.5 \mathrm{kDa}$ was expressed in the early and mid placenta. In contrast, it was not detected in the term placenta. There was no significant difference in the levels of the soluble form of BTC protein between early placentas and mid placentas. 


\section{Expression of ErbB-1 and ErbB-4 in human placenta}

The expression of erbB- 1 and erbB- 4 mRNA in placental tissues was identified by RT-PCR analysis throughout pregnancy. Quantitative RT-PCR with Southern blot analysis revealed that the levels of erbB- 1 mRNA in the early placentas were comparable to those in mid placentas and that they were significantly higher than those in term placentas. In contrast, the levels of erbB-4 mRNA in early placentas were significantly lower than those in mid and term placentas. There was no significant difference in the levels of erbB-4 mRNA between mid and term placentas (Fig. 4). Figure 5 shows immunolocalization of ErbB-1 and ErbB-4 in human placenta over the course of pregnancy. ErbB-1 was immunolocalized in C-cells in very early placentas (Fig. 5A), whereas it was immunolocalized in S-cells from early until term placentas, being more abundant in early placentas and less abundant in mid and term placentas (Fig. 5B-D). No immunostaining of ErbB-1 was noted in EVTs throughout pregnancy (data not shown). In contrast, ErbB-4 from very early until mid placentas was immunolocalized in S-cells, being more abundant in very early and early placentas and less abundant in mid placentas (Fig. 5E-G). There was no immunostaining of ErbB-4 in villous trophoblasts in term placentas (Fig. 5H), whereas ErbB-4 was immunolocalized in EVTs in term placentas (Fig. 5K). EVTs in term placentas were identified with ErbB-2 immunostaining (Fig. 5I, J) as well as with cytokeratin 7 immunostaining (data not shown). Immunolocalization of ErbB-4 in EVTs was observed in early and mid placentas (data not shown). Replacement of the primary antibody with non-immune murine IgG resulted in a lack of positive immunostaining in the cytoplasm of S-cells in early term placentas (Fig. 5L)

\section{Discussion}

In the present study, we have demonstrated, for the first time, that levels of BTC mRNA and the soluble form of BTC protein expression are higher in early and mid placentas than those of term placentas and that BTC is immunolocalized in the S-cells in the villous trophoblasts in early and mid placentas. We have also shown that higher levels of erbB-1 mRNA are found in early placentas than in term placentas. ErbB-1 in very early placentas was immunolocalized in C-cells, whereas ErbB-1 in early, mid and term placentas was immunolocalized in S-cells. These results are consistent with our previous reports using immunohistochemical analysis $(6,31)$. These findings imply that BTC in S-cells may act in a paracrine fashion in very early placentas and in an autocrine fashion in early and mid placentas via ErbB-1 in villous trophoblasts. In our previous study regarding the biological effect of
EGF in human placenta, we found that EGF in C-cells stimulates trophoblast proliferation in very early placentas, whereas EGF in S-cells stimulates and regulates differentiated trophoblast function in early placentas $(8,32)$. It is evident that EGF induces the differentiation in explants of trophoblastic tissues obtained from normal early placentas (31) and in long term serumfree culture of isolated trophoblasts (33). Little information is, however, available regarding the role of BTC on villous trophoblasts in early placentas. BTC acts as a potent mitogen for a variety of cells with a potency nearly identical to that of $\operatorname{EGF}(14,16)$, whereas BTC contributes to cell differentiation and the induction of cell function in various cells $(17,18$, 34). In the present study, expression of BTC and ErbB-1 was higher in early placentas than in term placentas, and BTC immunolocalized in S-cells in villous trophoblasts which display various functions indispensable for the maintenance of pregnancy and fetal growth in spite of the lack of cell proliferation. These findings suggest that BTC may predominantly promote the differentiated villous trophoblastic function in an autocrine fashion in early placentas. In contrast, BTC in term placentas is immunolocalized in EVTs, but not in villous trophoblasts. By definition, EVTs comprise all the trophoblastic elements located outside the villi. They are largely composed of uninuclear cells, and syncytial or multinucleated elements of EVTs are present in the deeper parts of the junctional zone. The proliferative phenotype of EVTs has been identified as proliferating cells, whereas the invasive phenotype of EVTs shows invasive characteristics $(35,36)$. BTC expressed in term placentas may contribute to placental growth through the maintenance of the EVT cell proliferation or invasive characteristics.

We have also demonstrated, for the first time, that erbB-4 mRNA is expressed in human placenta over the course of pregnancy. The quantitative RT-PCR analysis of erbB-4 mRNA revealed that the levels of erbB-4 in early placentas were significantly lower than those in mid and term placentas. Immunohistochemical analysis revealed that ErbB-4 in villous trophoblasts is noted in S-cells from very early until mid placentas but not in term placentas. In contrast, immunolocalization of ErbB-4 in term placentas is predominantly observed in EVTs. In the current study, the binding affinity to BTC of ErbB-1 homodimers is comparable to that of ErbB-4 homodimers (13). Furthermore, recent study has shown that appropriate biological responsiveness to ErbB ligands is determined by the levels of expression of specific ErbB receptor combinations (37). Especially, the ability of ErbB-4 to mediate signal transduction through EGF family ligands can be profoundly altered by the concomitant expression of ErbB-2 (38). ErbB-2 protein is strongly expressed in EVTs but not villous trophoblasts over the course of pregnancy, whereas ErbB-1 protein expression is not detected in EVTs (28). These findings suggest the possibility that BTC expressed 

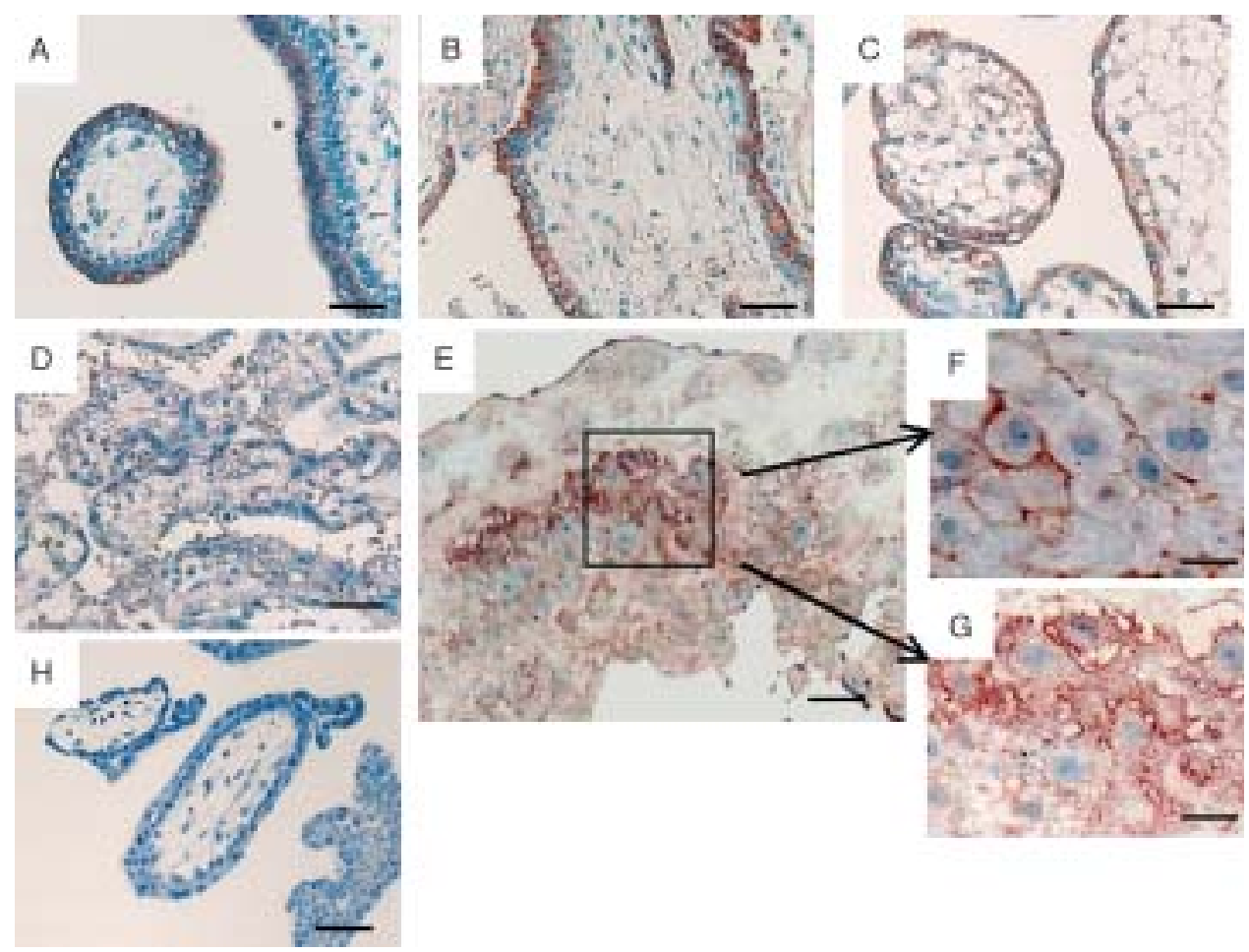

Figure 3 Immunohistochemical staining of formalin-fixed paraffin-embedded sections of human placentas with a polyclonal antibody to recombinant BTC protein. BTC in villous trophoblasts was immunolocalized in S-cells in very early placentas (A), early placentas (B) and mid placentas (C). No immunostaining of BTC in villous trophoblasts was noted in term placentas (D), whereas BTC was immunolocalized in EVTs in term placentas (E, G). EVTs in term placentas were identified with ErbB-2 immunostaining (F). Replacement of the primary antibody with non-immune goat IgG showed a lack of positive immunostaining for BTC protein in S-cells in early placenta $(\mathrm{H})$. Bars $=50 \mu \mathrm{m}(\mathrm{A}, \mathrm{B}, \mathrm{C}, \mathrm{D}, \mathrm{E}, \mathrm{H}), 20 \mu \mathrm{m}(\mathrm{F}, \mathrm{G})$.
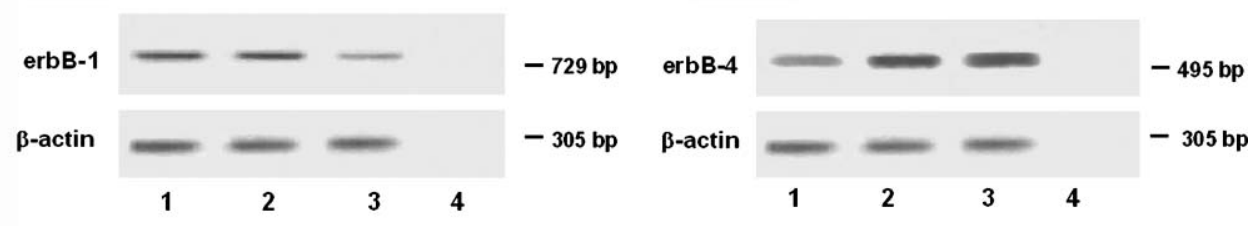

A
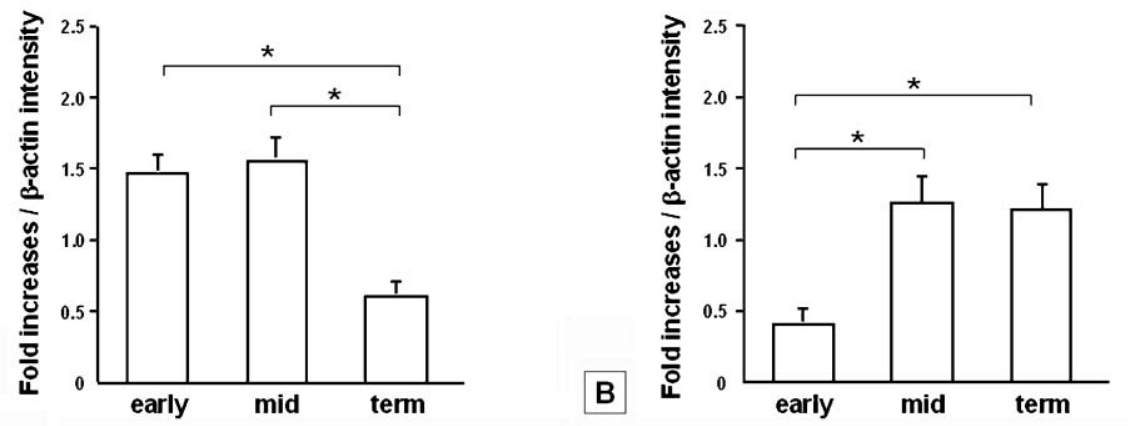

Figure 4 (Upper panels) Expression of erbB-1 and erbB-4 mRNA in human placentas, as assessed by quantitative RT-PCR analysis with Southern blotting. First strand CDNA was synthesized from total RNA extracted from early, mid and term placental tissues. Each $0.1 \mu \mathrm{g} \mathrm{cDNA}$ was subjected to RT-PCR with Southern blotting as described in Materials and methods. The 729 bp PCR product specific for erbB-1, the $495 \mathrm{bp}$ PCR product specific for erbB-4 and the $305 \mathrm{bp} \mathrm{PCR}$ product specific for $\beta$-actin were detected on the nylon membrane by the radioautograms. Experiments were repeated four times with similar results for each. (A) erbB-1. (B) erbB-4. Lane 1, early placenta; lane 2, mid placenta; lane 3, term placenta; lane 4, negative control. (Lower panels) Densitometric analysis of erbB-1 and erbB-4 mRNA levels in human placenta was performed as described in Materials and methods. The amount of mRNA of erbB-1 and erbB-4 was expressed relative to the abundance of $\beta$-actin mRNA. Data are presented as the fold increases over the average intensity of $\beta$-actin mRNA expressed from early until term placentas. Each value is expressed as the mean \pm S.D.; * $P<0.01$. The levels of erbB-1 mRNA in the early placentas were comparable to those in mid placentas, whereas they were significantly higher than those in term placentas. In contrast, the levels of erbB-4 mRNA in early placentas were significantly lower than those in mid or term placentas. 


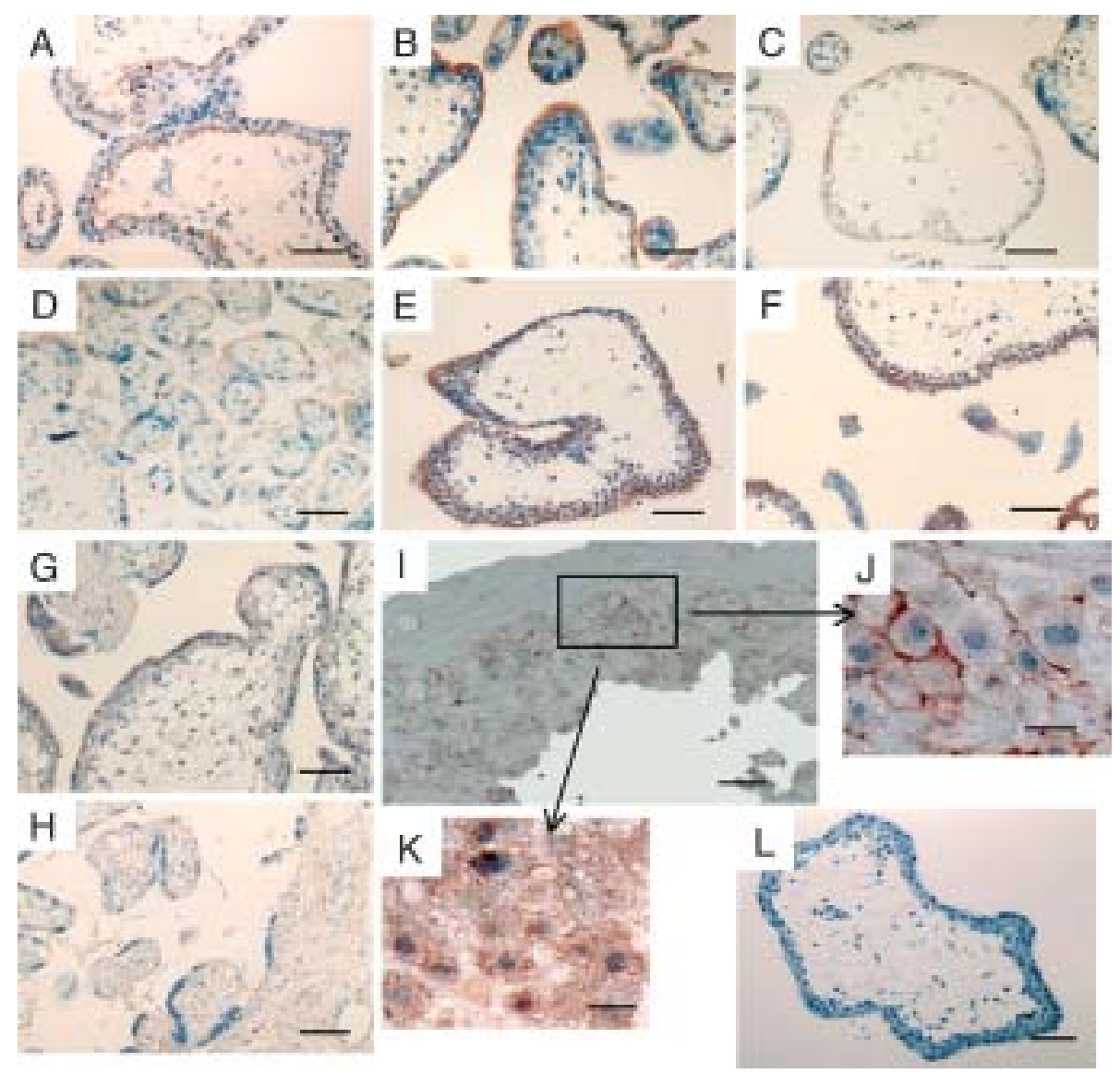

Figure 5 Immunohistochemical staining of formalin-fixed paraffin-embedded sections of human placentas with a monoclonal antibody to ErbB-1 or ErbB-4. ErbB-1 was immunolocalized in C-cells in very early term placentas (A) and in S-cells in early (B), mid (C) and term (D) placentas. ErbB-4 in very early placentas $(E)$, early placentas $(F)$ and mid placentas $(G)$ was immunolocalized in S-cells in villous trophoblasts. No immunostaining of ErbB-4 in villous trophoblasts in term placentas $(H)$ was noted. EVTs in term placentas were identified with ErbB-2 immunostaining $(\mathrm{I}, \mathrm{J})$. ErbB-4 was immunolocalized in EVTs in term placentas $(\mathrm{K})$. Replacement of the primary antibody with non-immune murine IgG showed a lack of positive immunostaining for ErbB-1 or ErbB-4 in S-cells in early placentas (L). Bars $=50 \mu \mathrm{m}(\mathrm{A}, \mathrm{B}, \mathrm{C}, \mathrm{D}, \mathrm{E}, \mathrm{F}, \mathrm{G}, \mathrm{H}, \mathrm{L}), 33 \mu \mathrm{m}(\mathrm{I}), 20 \mu \mathrm{m}(\mathrm{J}, \mathrm{K})$.

in EVTs in term placentas may act in an autocrine fashion via ErbB-4 homodimer or ErbB-2 and ErbB-4 heterodimer complex.

A common feature of the EGF family members is that they are synthesized as transmembrane precursor molecules, which are proteolytically processed to release the soluble mature growth factor from the cell surface (39). The soluble mature form is regarded as an autocrine or a paracrine growth factor in various tissues, whereas the transmembrane form is thought to have juxtacrine activity, which is recognized as the interactions of an immobilized growth factor with neighboring cells (40). Indeed, recent investigation regarding HB-EGF has shown that the biological effects of the transmembrane form on human luteinized granulosa cells are different from those of the soluble form (41). Similar to other members of the EGF family, BTC is synthesized as a transmembrane precursor, which is subject to proteolytic cleavage of its ectodomain to produce a soluble mature growth factor (13). In the present study, we demonstrated the expression of the soluble form of BTC protein with western immunoblot analysis using a polyclonal antibody raised against human recombinant BTC. With western immunoblot using the antibody recognizing the transmembrane form of BTC protein, Tada et al. (42) demonstrated that BTC cDNA transfected cells produce isoforms of the transmembrane form of BTC with molecular masses of approximately 21, 25, 29 and $40 \mathrm{kDa}$. The cytological localization of the transmembrane form of BTC protein without proteolytical cleavage can be clarified with immunostaining using the antibody specific for the soluble form of BTC protein. Further study will be needed to clarify the expression of the transmembrane forms with proteolytical cleavage in human placenta.

In conclusion, we have provided, for the first time, evidence for the changes in expression and cytological localization of BTC and its receptors, ErbB-1 and ErbB4 , in the trophoblasts in human placenta during the 
course of pregnancy. It seems likely that BTC, as well as EGF, is responsible for the placental growth and stimulation of function in the human placenta, acting as a local growth factor. BTC may play a pivotal role in promoting the differentiated villous trophoblastic function via ErbB-1 in early placentas and in contributing to placental growth through the maintenance of EVT cell function via ErbB-4 in term placentas. Further investigations using cell cultures obtained from human trophoblasts will be needed to shed light on the biological effects of BTC on villous trophoblasts or EVTs in human placenta.

\section{Acknowledgements}

This work was supported, in part, by a Grant-in-Aid for Scientific Research 12877263 from the Japanese Ministry of Education, Science and Culture and by the Japan Association of Obstetricians and Gynecologists Ogyaa-Donation Foundation (JODF).

\section{References}

1 Ishihara N, Matsuo H, Murakoshi H, Laoag-Fernandez J, Samoto T \& Maruo T. Changes in proliferative potential, apoptosis and Bcl-2 protein expression in cytotrophoblasts and syncytiotrophoblast in human placenta over the course of pregnancy. Endocrine Journal $200047317-327$

2 Maruo T, Ishihara N, Samoto T, Murakoshi H, Laoag-Fernandez JB \& Matsuo H. Regulation of human trophoblast proliferation and apoptosis during pregnancy. Early Pregnancy 20015 28-29.

3 Ishihara N, Matsuo H, Murakoshi H, Laoag-Fernandez JB, Samoto T \& Maruo T. Increased apoptosis in the syncytiotrophoblast in human term placentas complicated by either preeclampsia or intrauterine growth retardation. American Journal of Obstetrics and Gynecology $2002 \mathbf{1 8 6} 158-166$.

4 Maruo T, Matsuo H \& Mochizuki M. Thyroid hormone as a biological amplifier of differentiated trophoblast function in early pregnancy. Acta Endocrinologica 1991125 58-66.

5 Maruo T, Murata K, Matsuo H, Samoto T \& Mochizuki M. Insulinlike growth factor-I as a local regulator of proliferation and differentiated function of the human trophoblast in early pregnancy. Early Pregnancy 19951 54-61.

6 Maruo T \& Mochizuki M. Immunohistochemical localization of epidermal growth factor receptor and myc oncogene product in human placenta: implication for the trophoblast proliferation and differentiation. American Journal of Obstetrics and Gynecology $1987156721-727$.

7 Ladines-Llave CA, Maruo T, Malano AS \& Mochizuki M. Cytologic localization of epidermal growth factor and its receptor in developing human placenta varies over the course of pregnancy. American Journal of Obstetrics and Gynecology 1991 $1651377-1382$.

8 Maruo T, Matsuo H, Murata K \& Mochizuki M. Gestational agedependent dual action of epidermal growth factor on human placenta early in gestation. Journal of Clinical Endocrinology and Metabolism $1992751362-1367$.

9 Matsuo T, Maruo T, Murata K \& Mochizuki M. Human early placental trophoblasts produce an epidermal growth factor-like substance in synergy with thyroid hormone. Acta Endocrinologica $1993128225-229$.

10 Garcia-Lloret MI, Yui J, Winkler-Lowen B \& Guilbert LJ. Epidermal growth factor inhibits cytokine-induced apoptosis of primary human trophoblast. Journal of Cellular Physiology $1996 \mathbf{1 6 7}$ 324-332.

11 Pijnenborg R, Luyten C, Vercruysse L, Keith JC Jr \& Van Assche FA. Cytotoxic effects of tumour necrosis factor (TNF)-alpha and interferon-gamma on cultured human trophoblast are modulated by fibronectin. Molecular Human Reproduction 2000 6 635-641.

12 Groenen LC, Nice EC \& Burgess AW. Structure-function relationships for the EGF/TGF-alpha family of mitogens. Growth Factors $199411235-257$.

13 Dunbar AJ \& Goddard C. Structure-function and biological role of betacellulin. International Journal of Biochemistry and Cell Biology $200032805-815$

14 Shing Y, Christofori G, Hanahan D, Ono Y, Sasada R, Igarashi K et al. Betacellulin: a mitogen from pancreatic beta cell tumors. Science 1993259 1604-1607.

15 Sasada R, Ono Y, Taniyama Y, Shing Y, Folkman J \& Igarashi K. Cloning and expression of cDNA encoding human betacellulin, a new member of the EGF family. Biochemical and Biophysical Research Communications 1993190 1173-1179.

16 Watanabe T, Shintani A, Nakata M, Shing Y, Folkman J, Igarashi $\mathrm{K}$ et al. Recombinant human betacellulin. Molecular structure, biological activities, and receptor interaction. Journal of Biological Chemistry $19942699966-9973$.

17 Christophe J. Pancreatic tumoral cell line AR42J: an amphicrine model. American Journal of Physiology 1994266 G963-G971.

18 Watada H, Kajimoto Y, Miyagawa J, Hanafusa T, Hamaguchi K, Matsuoka T et al. PDX-1 induces insulin and glucokinase gene expressions in alphaTC1 clone 6 cells in the presence of betacellulin. Diabetes $1996451826-1831$.

19 Hofmann GE, Horowitz GM, Scott RT Jr \& Navot D. Transforming growth factor-alpha in human implantation trophoblast: immunohistochemical evidence for autocrine/paracrine function. Journal of Endocrinology and Metabolism 199376 781-785.

20 Lysiak JJ, Johnson GR \& Lala PK. Localization of amphiregulin in the human placenta and decidua throughout gestation: role in trophoblast growth. Placenta 199516 359-366.

21 Birdsall MA, Hopkisson JF, Grant KE, Barlow DH \& Mardon HJ. Expression of heparin-binding epidermal growth factor messenger RNA in the human endometrium. Molecular Human Reproduction $1996231-34$

22 Yamada T, Nakago S, Kurachi O, Matsuo H \& Maruo T. Progesterone down-regulates insulin-like growth factor-I expression in cultured human uterine leiomyoma cells. Human Reproduction $200419215-321$.

23 Adam RM, Borer JG, Williams J, Eastham JA, Loughlin KR \& Freeman MR. Amphiregulin is coordinately expressed with heparin-binding epidermal growth factor-like growth factor in the interstitial smooth muscle of the human prostate. Endocrinology $19991405866-5875$.

24 Patel NV, Acarregui MJ, Snyder JM, Klein JM, Sliwkowski MX \& Kern JA. Neuregulin-1 and human epidermal growth factor receptors 2 and 3 play a role in human lung development in vitro. American Journal of Respiratory Cell and Molecular Biology $20004432-440$.

25 Shimomura Y, Matsuo H, Samoto T \& Maruo T. Up-regulation by progesterone of proliferating cell nuclear antigen and epidermal growth factor expression in human uterine leiomyoma. Journal of Clinical Endocrinology and Metabolism 199782 293-299.

26 Bradford MM. A rapid and sensitive method for the quantitation of microgram quantities of proteins utilizing the principle of protein-dye binding. Analytical Biochemistry $1976 \mathbf{7 2} 248-253$.

27 Maruo T \& Mochizuki M. Immunohistochemical localization of epidermal growth factor receptor and myc oncogene product in human placenta: implication for trophoblast proliferation and differentiation. American Journal of Obstetrics and Gynecology $1987156721-727$.

28 Jokhi PP, King A \& Loke YW. Reciprocal expression of epidermal growth factor receptor (EGF-R) and c-erbB-2 by non-invasive and invasive human trophoblast population. Cytokine 19946 433-442. 
29 Leach RE, Romero R, Kim YM, Chalworapongsa T, Kilburn B, Das SK et al. Pre-eclampsia and expression of heparin-binding EGF-like growth factor. Lancet 2002360 1215-1219.

30 Quenby S, Brazeau C, Drakeley A, Lewis-Jones DI \& Vunce G. Oncogene and tumour suppressor gene products during trophoblast differentiation in the first trimester. Molecular Human Reproduction 19984 477-481.

31 Maruo T, Matsuo H, Oishi T, Hayashi M, Nishino R \& Mochizuki M. Induction of differentiated trophoblast function by epidermal growth: relation of immunohistochemically detected cellular epidermal growth factor receptor levels. Journal of Endocrinology and Metabolism 198764 744-750.

32 Filla MS, Zhang CX \& Kaul KLA. Potential transforming growth factor alpha/epidermal growth factor receptor autocrine circuit in placental cytotrophoblasts. Cell Growth and Differentiation $19934387-393$

33 Morrish DW, Bhardwaj D, Dabbagh L, Marusyk H \& Siy O. Epidermal growth factor induces differentiation and secretion of human chorionic gonadotropin and placental lactogen in normal human placenta. Journal of Clinical Endocrinology and Metabolism $1987651282-1290$.

34 Ishiyama N, Kanzaki M, Seno M, Yamada H, Kobayashi I \& Kojima I. Studies on the betacellulin receptor in pancreatic AR42J cells. Diabetologia $199841623-628$.

35 Kaufmann P \& Castellucci M. Extravillous trophoblast in the human placenta. Trophoblast Research 199710 21-65.

36 Huppertz B, Kertschanska S, Demir AY, Frank HG \& Kaufmann P. Immunohistochemistry of matrix metalloproteinases (MMP), their substrates, and their inhibitors (TIMP) during trophoblast invasion in the human placenta. Cell and Tissue Research 1998 291 133-148.

37 Sundaresan S, Roberts PE, King KL, Sliwkowski MX \& Mather JP. Biological response to ErbB ligands in nontransformed cell lines correlates with a specific pattern of receptor expression. Endocrinology $19981394756-4764$.

38 Wang LM, Kuo A, Alimandi M, Veri MC, Lee CC, Kapoor V et al. ErbB2 expression increases the spectrum and potency of ligandmediated signal transduction through ErbB4. PNAS 199895 6809-6814.

39 Massague J \& Pandiella A. Membrane-anchored growth factors. Annual Review of Biochemistry 199362 515-541.

40 Raab G \& Klagsbrun M. Heparin-binding EGF-like growth factor. Biochimica et Biophysica Acta 19971333 F179-199.

41 Pan B, Sengoku K, Goishi K, Takuma N, Yamashita T, Wada K et al. The soluble and membrane-anchored forms of heparin-binding epidermal growth factor-like growth factor appear to play opposing roles in the survival and apoptosis of human luteinized granulosa cells. Molecular Human Reproduction 20028 734-741.

42 Tada H, Sasada R, Kawaguchi Y, Kojima I, Gullick WJ, Salomon DS et al. Processing and juxtacrine activity of membraneanchored betacellulin. Journal of Cellular Biochemistry $1999 \mathbf{7 2}$ 423-434.

Received 1 October 2003

Accepted 24 March 2004 